\title{
Design of an Omnidirectional High Gain Antenna Array
}

\author{
M. Liu \\ Department of Electronic Technology, Tianjin Electronic Information College
}

China

\begin{abstract}
In order to obtain the performance of high gain and omnidirectional radiation pattern, an antenna array composed of four elements is proposed in this paper. The antenna achieves a bandwidth of $8.5 \%(190 \mathrm{MHz})$ for a return loss $(\mathrm{RL})<-10 \mathrm{~dB}$ at centre frequency. The antenna has omnidirectional radiation pattern in H-plane with maximum gain of $7.8 \mathrm{~dB}$ and $3 \mathrm{~dB}$ beamwidth of $20^{\circ}$. The micro-strip structure makes antenna has advantage of compactness and ease of integration with feeding network.
\end{abstract}

\section{Keywords-omnidirectional; vertical polarized; antenna array}

\section{INTRODUCTION}

With the rapid development of wireless communication system, spectrum resources become more and more crowded. In order to avoid mutual interference between communication systems, directional radiation forms have been applied widely. But in some special systems, such as wireless LAN system (WLAN) or wireless data monitoring system, omnidirectional antenna is essential, so it still be a research focus. More and more attention on the study of antenna structures with new and newer characteristics and monopole-like radiation pattern is paid. For example, dielectric resonator antennas (DRAs) have attracted a group of researchers due to their several attractive features well discussed in previous articles $[1,2]$.

Recently, omnidirectional antennas applied widely are divided into two kinds: one is electric monopole, dipole or monopole-like [3, 4], the other is planar antenna and circular disc antenna $[5,6]$. The antennas mentioned above have some common characteristics such as their simple structure and stable performance. Not only radiation gain is not high, but also high gain is difficult to realize using antenna array because of special antenna form.

On the basis research of vertical polarization element with radiation pattern like an electric monopole, antenna elements are combined to array for solving radiation gain and remote communication issue. Antenna array greatly improves radiation gain with constant bandwidth. The antenna proposed achieves a bandwidth of $8.5 \%(190 \mathrm{MHz})$ for a return loss (RL) $<-10 \mathrm{~dB}$ at centre frequency, and it has omnidirectional radiation pattern in $\mathrm{H}$-plane with maximum gain of $7.8 \mathrm{~dB}$ and $3 \mathrm{~dB}$-beamwidth of $20^{\circ}$.

\section{ANTENNA DESIGN}

The antenna array shown in fig. 2 consists of four elements. The antenna is fabricated on "Rogers RT/duroid 5880" with dielectric constant $\varepsilon \quad r=2.2$ and thickness $h=1.52 \mathrm{~mm}$. Each element shown in fig.1 includes dielectric substrate, rectangular radiation patch, feeding network and ground plane. The matching stub lines are merged into array for tuning impedance matching.

When the width of ground plane is equal to dielectric substrate, antenna has directional radiation pattern, however, when the width of ground plane is much less than dielectric substrate, the defect ground structure enables electromagnetic wave to radiate back by penetrating substrate, which forming an omnidirectional pattern.

The dielectric substrate, rectangular radiation patch and matching stub line have dimensions of $a \times b, c \times d$ and exf, respectively. The width of ground plane is $w$.

The width of rectangular radiation patch is closely related to the antenna's resonant frequency and its value is calculated by the following equation.

$$
c=\frac{\lambda_{0}}{2 \sqrt{\varepsilon_{e}}}-2 \Delta l
$$

Where, $\varepsilon$ e is effective permittivity, $\triangle 1$ is correctional value. $\varepsilon$ e and $\triangle 1$ is given by

$$
\begin{aligned}
& \varepsilon_{e}=\frac{\varepsilon_{r}+1}{2}+\frac{\varepsilon_{r}-1}{2}\left(1+\frac{10 h}{d}\right)^{-1 / 2} \\
& \Delta l=0.412 h \frac{\left(\varepsilon_{e}+0.3\right)(d / h+0.264)}{\left(\varepsilon_{e}-0.258\right)(d / h+0.8)}
\end{aligned}
$$

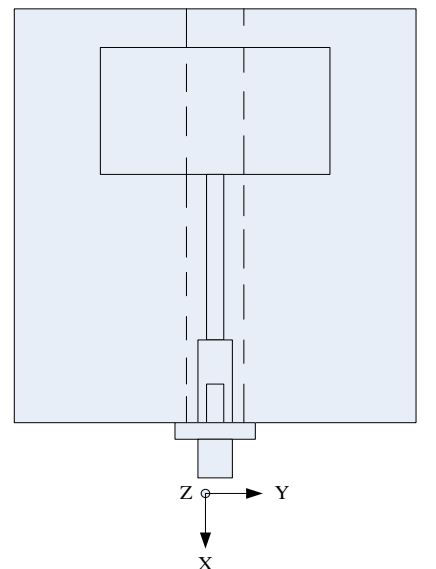

FIGURE I. THE STRUCTURE OF THE ANTENNA ELEMENT 


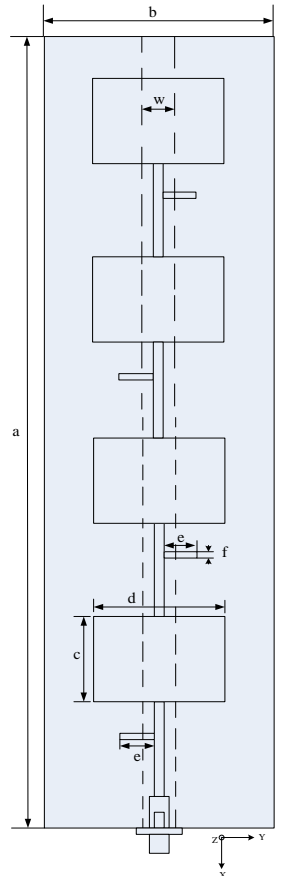

FIGURE II. THE STRUCTURE OF THE ANTENNA ARRAY.

According to experience, the width of rectangular radiation patch has a pronounced effect on resonant frequency. With the increasing of $\mathrm{c}$, resonant frequency gradually reduces while keeping other geometrical parameters constant. The width of feeding line and matching stub lines mainly affect the impedance matching of antenna. Through optimum design, the antenna obtains good and stable matching performance whiles the width of rectangular radiation patch and ground plane varies within certain limits.

\section{RESULTS AND DISCUSSION}

By adjusting the geometrical parameters, we obtain the frequency desired, good impedance matching and radiation performance. The performances of the antenna proposed are simulated and optimized by HFSS. The final size is $\mathrm{a}=375 \mathrm{~mm}, \mathrm{~b}=80 \mathrm{~mm}, \mathrm{c}=45 \mathrm{~mm}, \mathrm{~d}=54 \mathrm{~mm}, \mathrm{w}=7.5 \mathrm{~mm}, \mathrm{e}=0.9 \mathrm{~mm}, \mathrm{f}=$ $10 \mathrm{~m}, \varepsilon \mathrm{r}=2.2$, and $\mathrm{h}=1.52 \mathrm{~mm}$. The final results are shown in fig.3-5.

Fig.3 shows that the antenna achieves an impedance bandwidth of $8.5 \%(2120 \sim 2310 \mathrm{MHz})$ at centre frequency. Fig.4 indicates that $3 \mathrm{~dB}$-beamwidth in E-plane is $20^{\circ}$. From fig.5 we can see that the antenna has omnidirectional radiation pattern in $\mathrm{H}$-plane with maximum gain of $7.8 \mathrm{~dB}$ and the roundness of pattern is $\pm 1.3 \mathrm{~dB}$.The maximum and minimum gain of antenna element is $3.2 \mathrm{~dB}$ and $0.7 \mathrm{~dB}$ and the roundness of pattern is $\pm 1.25 \mathrm{~dB}$. Comparing element with array, it can be found that minimum gain occurs at left and right side of dielectric substrate, maximum gain occurs at the normal direction of radiation patch. The gain of back is less than front. According to theoretical analysis, the phenomena is caused by energy loss while electromagnetic wave penetrating substrate to back.
According to array theory, the gain of array composed of four elements should be $6 \mathrm{~dB}$ higher than single element. The actual value is $4.6 \mathrm{~dB}$, less than theoretical value, which is caused by the form of feeding in series. From the fact we can deduce that if the number of element continues to increase, the growth of radiation gain will slow down and the gain of array will eventually tend to a stable value.

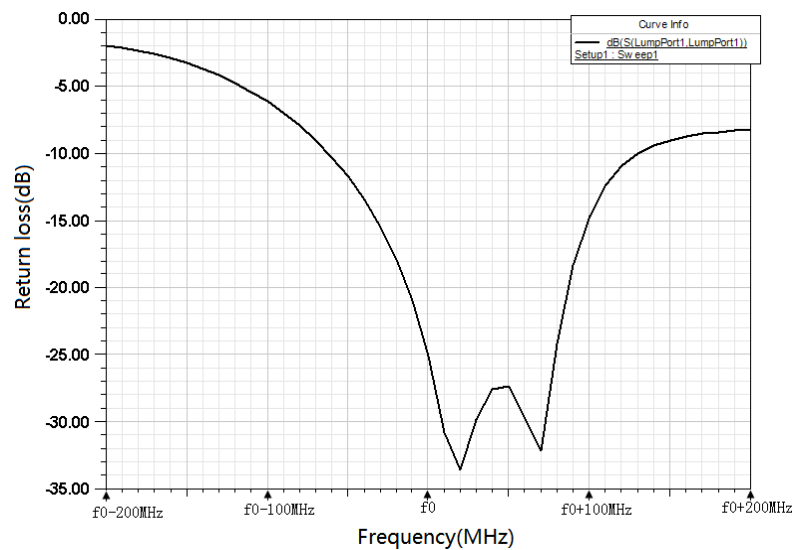

FIGURE III. SIMULATED RETURN LOSS.

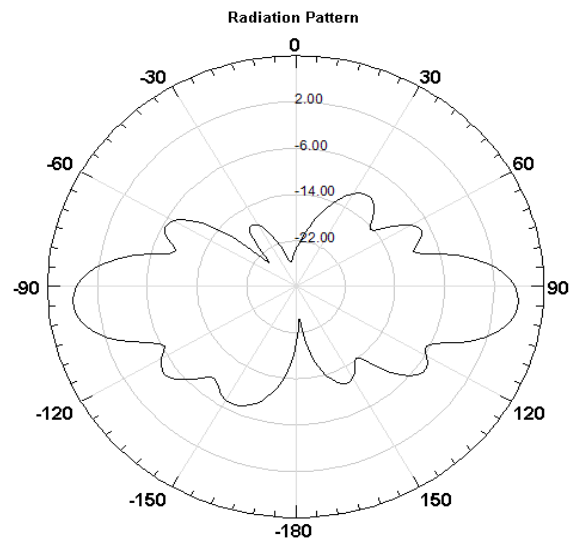

FIGURE IV. RADIATION PATTERN IN E-PLANE.

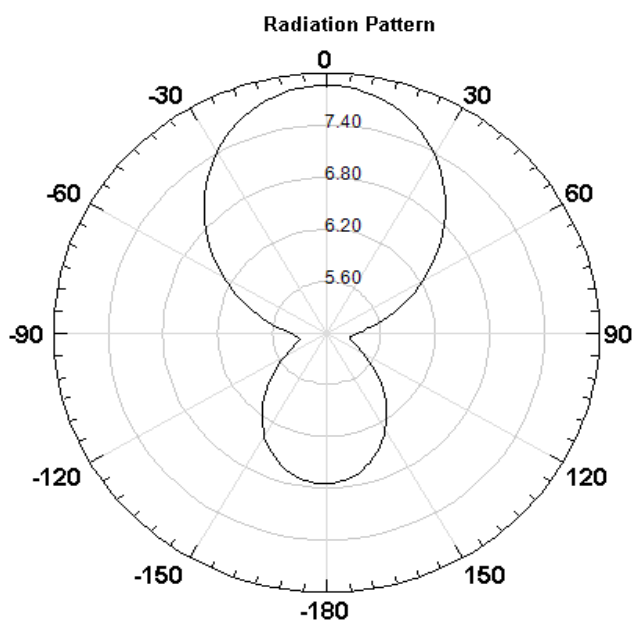

FIGURE V. RADIATION PATTERN IN H-PLANE. 


\section{CONCLUSION}

Through the improvement of directional micro-strip antenna, using defect ground structure, omnidirectional radiation characteristic can be achieved. The antenna proposed has common advantages of micro-strip antenna such as low profile, light weight, low cost and easily fabricated. In addition, the antenna elements can be combined to array for higher gain because of micro-strip feeding form.

The omnidirectional micro-strip antenna is used as an element to combine into a four-element antenna array. Results indicate that the array proposed has vertical polarization radiation, omnidirectional pattern, maximum gain of $7.8 \mathrm{~dB}$ and 3dB-beamwidth of $20^{\circ}$ with constant relative bandwidth compared with single element. All above mentioned verify the feasibility of antenna design. High gain can save transmit energy, which meets the requirement of remote communication. Therefore, the antenna array proposed will have a good potential in communication systems.

\section{REFERENCES}

[1] Marc Lapierre, Yahia M.M. Antar, A. Ittipiboon \& A. Petosa, Ultra wideband monopole dielectric resonator antenna. IEEE Microwave and Wireless Components Letters, Vol.15, No.1, 2005.

[2] Debatosh Guha, Yahia M.M. Antar, A. Ittipiboon, A. Petosa \& David Lee, Improved design guidelines for the ultra wideband monopoledielectric resonator antenna. IEEE Antennas and Wireless Propagation Letters, Vol.5, pp. 373-376, 2006.

[3] Debatosh Guha \& Yahia M.M. Antar. New half-hemispherical dielectric resonator antenna for broadband monopole-type radiation. IEEE Transaction on antenna and propagation. Vol.54, No.12, pp. 3621-3628, 2006.

[4] Mapierre L, Antar Y M M \& Ittipiboon A. Ultra wideband monopole dielectric resonator antenna. IEEE Microwave and Wireless Components Letters. Vol.15, No.1, pp. 7-9, 2005.

[5] W. Hong \& K. Sarabandi, Low profile miniaturized planar antenna with omnidirectional vertically polarized radiation, IEEE Trans. Antennas Propag. Vol.56, pp. 1533-1540, 2008.

[6] S. Cao, Y. Jiao, G. Zhao \& B. Yang, A compact planar inverted-F antenna for handset application, IEEE International Symposium on Microwave, Antenna, Propagation and WMC technologies for Wireless Communications, pp. 673-675, 2009. 